\title{
Erectile Dysfunction in Patients with Chronic Renal Failure
}

\author{
Leonardo E. Messina, Joaquim A. Claro, Archimedes Nardozza, Enrico Andrade, Valdemar \\ Ortiz, Miguel Srougi
}

Section of Urology, Paulista School of Medicine, Federal University of Sao Paulo, UNIFESP, Sao Paulo, SP, Brazil

\begin{abstract}
Objective: Determine the prevalence of erectile dysfunction in patients undergoing hemodialysis.

Materials and Methods: This cross-sectional study was carried out to determine the prevalence of erectile dysfunction in a population of 58 patients in hemodialysis program. Erectile dysfunction was assessed by using the International Index of Erectile Function (IIEF). Information on demographic data, renal failure, comorbidities, laboratory tests and search for medical treatment for erectile dysfunction by means of interviews and researches in medical charts was obtained. Student $\mathrm{t}$ test was utilized to compare the laboratory results between group of patients with and without erectile dysfunction. The chi-square test was utilized to compare the comorbidities and the characteristics of the population studied between the groups of patients with and without erectile dysfunction. The significance level considered was $5 \%$.

Results: Mean patient age was $50.2 \pm 14.6$ years and the time of hemodialysis was $30.4 \pm 28.4$ months. The prevalence of erectile dysfunction was $60.3 \%$. A progressive increase respecting the age was reported. In patients younger than 50 years, this prevalence reached $31.4 \%$ and in patients older than 50 years, this prevalence reached $68.6 \%$. With respect to the comorbidities, hypertensive patients prevailed with $94.8 \%$ of the total, whilst diabetic patients represented $24.9 \%$. However only the association between diabetes and erectile dysfunction was significant. Patients with erectile dysfunction presented significantly lower values for serum creatinine and $\mathrm{Kt} / \mathrm{V}$. There was no variation between the groups with reference to calcium, potassium, phosphorus, hematocrit, hemoglobin, pre- and post-dialysis urea values. There was no correlation between erectile dysfunction and time of dialysis. Amongst patients with erectile dysfunction, $8.6 \%$ sought medical care. Conclusions: The prevalence of erectile dysfunction in patients in hemodialysis program was of $60.3 \%$. Age, diabetes and hemodialysis characteristics are associated to higher incidence of erectile dysfunction.
\end{abstract}

Key words: erectile dysfunction; chronic renal failure; hemodialysis; questionnaires Int Braz. J Urol. 2007; 33: 673-8

\section{INTRODUCTION}

Life expectancy of patients with chronic renal failure (CRF) increased during the last decades with the improvement of renal replacement techniques - dialysis and renal transplantation. However, new complications or aggravation of preexisting diseases do impair the quality of life of these men. Erectile dysfunction (ED) is frequently observed in patients undergoing hemodialysis (HD) program, with prevalence ranging between $41 \%$ and $98 \%$ (1-12). From 1997, with the development of the International Index of Erectile Function (IIEF) (13), an instrument was created for uniform assessment of erectile dysfunc- 
tion, by standardizing the questions and classifying the answers into categories. This study has been developed to assess erectile dysfunction prevalence in patients with Chronic Renal Failure utilizing the IIEF.

\section{MATERIALS AND METHODS}

Seventy patients older than 18 years have been selected in two hemodialysis centers and from these 58 patients $(83 \%)$ agreed to participate in the research and signed the Informed Consent. The patients answered the IIEF questionnaire including the six questions about health-related determinants of the erectile function (questions number 1 to 5 and question number 15). The total score ranges from 1 to 30 , by being characterized as severe [1 to 6], moderate [7 to 12], mild to moderate [13 to 18], mild [19 to 24], and no dysfunction [25 to 30].

In the standard questionnaire applied sociodemographic data have been obtained (age, civil status and education level), presence of comorbidities (arterial hypertension and diabetes mellitus - DM) and time of hemodialysis.

Hematocrit, hemoglobin, calcium, phosphorus, potassium, pre- and post-dialysis urea and $\mathrm{Kt} / \mathrm{V}$ values have been all obtained from the medical charts, as well as the cause of the CRF.

Patients presenting ED were questioned if they have already searched for medical care for this problem.

Descriptive analysis of sociodemographic, clinic and laboratory data of the patients has been performed. The Student $t$ test was utilized to compare laboratory results between patients with and without ED. The chisquare $\left(\chi^{2}\right)$ test was utilized to compare the comorbidities and the characteristics of the population studied between the groups of patients with and without ED. The significance level considered was 5\%.

\section{RESULTS}

The study included fifty-eight (58) patients with age ranging from 21 to 76 years (mean age of $50.2 \pm 14.6$ years). The proportion between patients younger and older than 50 years was, respectively, $53.5 \%$ and $46.5 \%$. Patients undergone hemodialysis for a minimum period of one week and a maximum period of 102 months (mean of 30.4 \pm 28.4 months). Patients' data can be found in Table- 1 .

The prevalence of ED was $60.3 \%$ (Figure1). Progressive increase respecting the age was found. In patients younger than 50 years, the prevalence of ED was $31.4 \%$, reaching $68.6 \%$ in those patients older than 50 years $(\mathrm{p}<0.05)$.

No statistic association between sociodemographic variables and ED has been found.

Hypertensive patients prevailed in the study (94.8\%) with respect to the diabetic patients (24.9\%). However only the association between DM and ED was significant (Table-2).

Time of dialysis was not a factor associated to the presence of ED in the population under study.

Table 1 - Characteristics of the population studied.

\begin{tabular}{ccc}
\hline & $\begin{array}{c}\text { Number of } \\
\text { Patients }\end{array}$ & $\%$ \\
\hline Age $\quad$ 21 to 30 & 5 & 9 \\
31 to 40 & 12 & 21 \\
41 to 50 & 14 & 24 \\
51 to 60 & 9 & 16 \\
61 to 70 & 14 & 24 \\
71 to 80 & 4 & 7 \\
Ethnic group & & \\
$\quad$ White & 49 & 84.5 \\
$\quad$ Non-white & 9 & 15.5 \\
Education & & \\
$\quad$ None & 5 & 8.6 \\
$\quad$ Primary school & 42 & 72.4 \\
$\quad$ Secondary school & 11 & 19 \\
Civil status & & \\
$\quad$ Single & 6 & 10.3 \\
$\quad$ Married & 51 & 87.9 \\
$\quad$ Widower & 1 & 1.7 \\
Diabetes mellitus & & \\
$\quad$ Yes & 15 & 24.9 \\
$\quad$ No & 43 & 74.1 \\
Arterial hypertension & & \\
$\quad$ Yes & 55 & 94.8 \\
$\quad$ No & 3 & 5.2 \\
\hline
\end{tabular}




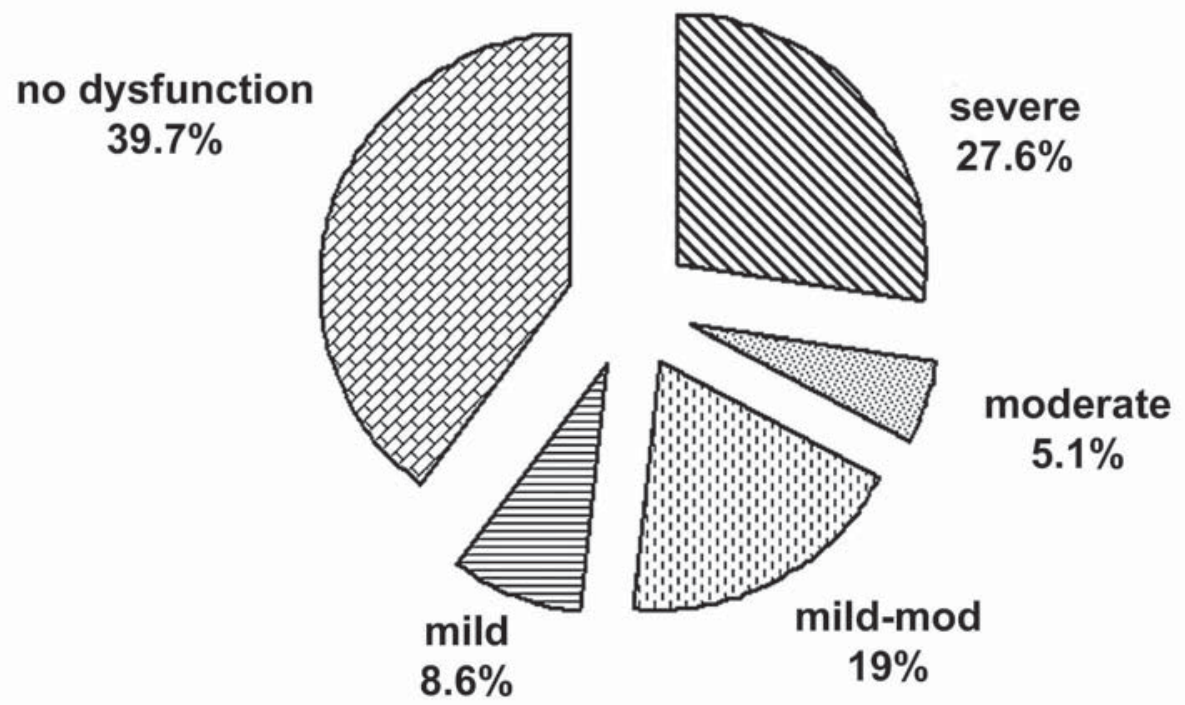

Figure 1-Erectile dysfunction in patients with chronic renal failure.

Table 2 - Results found in patients with and without erectile dysfunction (ED).

\begin{tabular}{|c|c|c|}
\hline & $\begin{array}{l}\text { Without ED } \\
\quad(\mathrm{N}=23)\end{array}$ & $\begin{array}{l}\text { With ED } \\
(\mathrm{N}=35)\end{array}$ \\
\hline \multicolumn{3}{|l|}{ Age } \\
\hline Up to 50 years of age & 20 & 11 \\
\hline Older than 51 years of age & 3 & $24 *$ \\
\hline \multicolumn{3}{|l|}{ Diabetes mellitus } \\
\hline No & 22 & 21 \\
\hline Yes & 1 & $14 *$ \\
\hline \multicolumn{3}{|l|}{ Arterial hypertension } \\
\hline No & 0 & 3 \\
\hline Yes & 23 & 32 \\
\hline Serum creatinine $(\mathrm{mg} / \mathrm{dL})^{+}$ & $15.9 \pm 4.5$ & $11.6 \pm 4.3^{*}$ \\
\hline Serum calcium $(\mathrm{mg} / \mathrm{dL})^{+}$ & $12.4 \pm 17.8$ & $8.7 \pm 0.8$ \\
\hline $\mathrm{KT} / \mathrm{V}^{\circ}$ & $1.2 \pm 0.4$ & $0.9 \pm 0.2 *$ \\
\hline Serum potassium $(\mathrm{mEq})^{+}$ & $4.8 \pm 0.7$ & $4.7 \pm 0.7$ \\
\hline Hematocrit $(\%)^{+}$ & $30.9 \pm 7.3$ & $28.5 \pm 7.5$ \\
\hline Hemoglobin $(\mathrm{g} / \mathrm{dL})^{+}$ & $9.8 \pm 2.3$ & $8.9 \pm 2.4$ \\
\hline Phosphorus $(\mathrm{mg} / \mathrm{dL})^{+}$ & $8.9 \pm 9.7$ & $6.3 \pm 1.7$ \\
\hline Pre urea $(\mathrm{mg} / \mathrm{dL})^{+}$ & $155.1 \pm 31.1$ & $151.9 \pm 38.8$ \\
\hline Post urea $(\mathrm{mg} / \mathrm{dL})^{\circ}$ & $62.0 \pm 24.5$ & $72.3 \pm 28.1$ \\
\hline
\end{tabular}

${ }^{+}=$data expressed as mean \pm standard deviation, $*=p<0.05$ 
Amongst the laboratory tests, only creatinine and the $\mathrm{Kt} / \mathrm{V}$ presented static statistic relation with the ED (Table-2).

Only three patients $(8.6 \%)$ searched medical treatment for ED.

\section{COMMENTS}

In our sample, the prevalence of ED was $60.3 \%$. Taking into consideration the only severe category, the prevalence was $27.6 \%$. Initial studies reported that ED in patients undergoing hemodialysis ranged between $41 \%$ and $93 \%$ (1-3). Since the methodology of such studies was not uniform, the comparison of the results found was not adequate. In studies in which the International Index of Erectile Function (IIEF) was utilized, the prevalence of ED ranged between $57.9 \%$ and $86.4 \%$ (4-12), evidencing that such dysfunction is frequent in patients with CRF (Table-3). Severe ED affects from $28 \%$ to $45 \%$ of these patients.

It is found in literature that ED is age-related $(6-8,12,14)$. By stratifying the age of our patients below and above 50 yeas of age, we found, respectively, $31.4 \%$ and $68.6 \%$, of ED prevalence.

The presence of hypertension found in our patients was $94.8 \%$. However, this association was not significant. Several studies with chronic renal patients found in literature do confirm this finding (1-8). Feldman et al. (15) pointed out the occurrence of severe ED in $15 \%$ of hypertensive patients treated against $9.6 \%$ in the general population. The study does

Table 3 - International Index of Erectile Function (IIEF) in man with chronic renal failure.

\begin{tabular}{lcrl}
\hline Author & Year & N & \% DE \\
\hline Turk, S et al. & 2001 & 35 & 71 \\
Rosas et al. & 2001 & 302 & 82 \\
Cerqueira et al. & 2002 & 119 & 57.9 \\
Arslan et al. & 2002 & 187 & 80.7 \\
Naya et al. & 2002 & 174 & 86.2 \\
Fernandes Neto et al. & 2002 & 118 & 86.4 \\
Ali ME et al. & 2005 & 75 & 82.5 \\
\hline
\end{tabular}

not indicate, however, if this association was originated from the hypertension or from the use of antihypertensive medication by considering that there is also an association between ED and the use of hypotensives. It can be argued that the high degree of vascular impairment (atherosclerosis) present in men with CRF undergoing hemodialysis is at least partially responsible for the erectile mechanism aggravation (15).

With reference to the DM, there was a significant statistic association to the ED. This study indicated that only one amongst the fifteen patients did not have ED. In the patients evaluated by Cerqueira et al. (5), 99\% of the diabetic patients presented ED. This association has been also found in other studies $(4,8,10,15)$.

No statistic association of ED has been found with reference to civil status, education or ethnic groups. In the MMAS longitudinal study, Johannes et al. (14) reported that the risk of developing age-related ED was higher in men with lower education degree. In our group, Moreira et al. (16) found that the education was inversely correlated to ED. Study carried out in four North-American cities, including 1,680 men older than 40 years of age, demonstrated that ED was not related to ethnic groups (17).

Time of dialysis was not also a factor associated to the presence of ED in the population under study, similar result was found by other authors (6-8).

$\mathrm{Kt} / \mathrm{V}$, measure of the quantity of plasma cleared of urea $(\mathrm{K} x \mathrm{t})$ divided by the volume of urea distribution (V) is an index utilized to assess dialysis adequacy. Patients with erectile dysfunction presented statistically significant lower values for Kt/V (0.9) when compared to patients without erectile dysfunction $(1.2)$. Some authors $(18,19)$ recommend one Kt/ $\mathrm{V}$ of 1.3 for providing adequate hemodialysis. Therefore, the indexes found in our study can indicate that a hemodialysis within acceptable standards may contribute to prevent ED. This relation has not been found in other studies $(1,4,7)$.

Miyata et al. (10) found in literature that higher values of hemoglobin were associated to severe ED. In our study, hematocrit and hemoglobin were both found to be higher in patients without $\mathrm{ED}$, when compared with those with ED, but they show no statistic difference. 
Amongst patients with ED, only three of them $(8.6 \%)$ sought medical guidance. In the studies with chronic renal patients, the search for medical treatment ranged between $1 \%$ and $9.6 \%(7,8)$. It is found in literature that less than $10 \%$ of men seek medical care for ED (20). Moreira et al. (21) found that the number of individuals with ED that sought medical help was of $42 \%$. The lack of approach regarding sexuality is caused, mostly, by health professionals that are not used to question the topic. The majority of the men doctors $(62.5 \%)$ and women doctors $(71.5 \%)$ reported that they do not routinely investigate the sexual function of the male patients. In a routine consultation, only $11.1 \%$ and $8.7 \%$ of the men doctors and women doctors, respectively, reported they were used to always investigate the sexual function of male patients. Amongst the patients, $78 \%$ of them did not refer about having problems to discuss sexual issues with their physicians (21).

\section{CONCLUSIONS}

The prevalence of ED in patients in hemodialysis program was $60.3 \%$. However, only $8.6 \%$ of these patients search for medical help. Age, diabetes and hemodialysis characteristics are associated with higher incidence of ED. Physicians and other health professionals shall pay attention to the erection problems in this group of patients in order to provide directions for an adequate medical treatment.

\section{CONFLICT OF INTEREST}

None declared.

\section{REFERENCES}

1. Rodger RS, Fletcher K, Dewar JH, Genner D, McHugh M, Wilkinson R, et al.: Prevalence and pathogenesis of impotence in one hundred uremic men. Uremia Invest. 1984-1985; 8: 89-96.

2. Breza J, Reznicek J, Pribylincova V, Zvara P.: Erectile dysfunctions in patients treated with hemodialysis and kidney transplantation. Bratisl Lek Listy. 1993; 94: 48993.
3. Palmer BF: Sexual dysfunction in uremia. J Am Soc Nephrol. 1999; 10: 1381-8.

4. Rosas SE, Joffe M, Franklin E, Strom BL, Kotzker W, Brensinger C, et al.: Prevalence and determinants of erectile dysfunction in hemodialysis patients. Kidney Int. 2001; 59: 2259-66.

5. Cerqueira J, Moraes M, Glina S.: Erectile dysfunction: prevalence and associated variables in patients with chronic renal failure. Int J Impot Res. 2002; 14: 65-71.

6. Naya Y, Soh J, Ochiai A, Mizutani Y, Ushijima S, Kamoi K, et al.: Significant decrease of the International Index of Erectile Function in male renal failure patients treated with hemodialysis. Int J Impot Res. 2002; 14: 172-7.

7. Neto AF, de Freitas Rodrigues MA, Saraiva Fittipaldi JA, Moreira ED Jr.: The epidemiology of erectile dysfunction and its correlates in men with chronic renal failure on hemodialysis in Londrina, southern Brazil. Int J Impot Res. 2002; 14 Suppl 2: S19-26.

8. Arslan D, Aslan G, Sifil A, Cavdar C, Celebi I, Gamsari T, et al.: Sexual dysfunction in male patients on hemodialysis: assessment with the International Index of Erectile Function (IIEF). Int J Impot Res. 2002; 14: 53942.

9. Krishnan R, Izatt S, Bargman JM, Oreopoulos D: Prevalence and determinants of erectile dysfunction in patients on peritoneal dialysis. Int Urol Nephrol. 2003; 35: $553-6$.

10. Miyata Y, Shindo K, Matsuya F, Noguchi M, Nishikido M, Koga S, et al.: Erectile dysfunction in hemodialysis patients with diabetes mellitus: association with age and hemoglobin A1c levels. Int J Urol. 2004; 11: 530-4.

11. Turk S, Karalezli G, Tonbul HZ, Yildiz M, Altintepe L, Yildiz A, et al.: Erectile dysfunction and the effects of sildenafil treatment in patients on haemodialysis and continuous ambulatory peritoneal dialysis. Nephrol Dial Transplant. 2001; 16: 1818-22.

12. Ali ME, Abdel-Hafez HZ, Mahran AM, Mohamed HZ, Mohamed ER, El-Shazly AM, et al.: Erectile dysfunction in chronic renal failure patients undergoing hemodialysis in Egypt. Int J Impot Res. 2005; 17: 180-5.

13. Rosen RC, Riley A, Wagner G, Osterloh IH, Kirkpatrick J, Mishra A: The international index of erectile function (IIEF): a multidimensional scale for assessment of erectile dysfunction. Urology. 1997; 49: 822-30.

14. Johannes CB, Araujo AB, Feldman HA, Derby CA, Kleinman KP, McKinlay JB: Incidence of erectile dysfunction in men 40 to 69 years old: longitudinal results from the Massachusetts male aging study. J Urol. 2000; 163:460-3. 
15. Feldman HA, Goldstein I, Hatzichristou DG, Krane RJ, McKinlay JB: Impotence and its medical and psychosocial correlates: results of the Massachusetts Male Aging Study. J Urol. 1994; 151: 54-61.

16. Moreira ED Jr, Lisboa Lobo CF, Villa M, Nicolosi A, Glasser DB: Prevalence and correlates of erectile dysfunction in Salvador, northeastern Brazil: a populationbased study. Int J Impot Res. 2002; 14 Suppl 2: S3-9.

17. Jonler M, Moon T, Brannan W, Stone NN, Heisey D, Bruskewitz RC: The effect of age, ethnicity and geographical location on impotence and quality of life. $\mathrm{Br}$ J Urol. 1995; 75: 651-5.

18. Hauk M, Kuhlmann MK, Riegel W, Kohler H: In vivo effects of dialysate flow rate on $\mathrm{Kt} / \mathrm{V}$ in maintenance hemodialysis patients. Am J Kidney Dis. 2000; 35: 10511.

19. Leon JB, Sehgal AR: Identifying patients at risk for hemodialysis underprescription. Am J Nephrol. 2001; 21: 200-7.

20. Driscoll CE, Garner EG, House JD. The effect of taking a sexual history on the notation of related diagnoses. Fam Med. 1986;18(5):293-5.

21. Moreira Jr ED, Abdo CHN, Santos DB, Wroclawski E, Fittipaldi JAS: Epidemiologia da disfunção erétil no Brasil: resultados da pesquisa nacional do "Projeto Avaliar”. Rev Bras Med. 2004; 61: 613-19.

Accepted after revision:

May 20, 2007

\author{
Correspondence address: \\ Dr. Leonardo Eiras Messina \\ Rua Arthur Gomes, 390, Centro \\ Sorocaba, SP, Brazil \\ Fax: + 55 153233-2529 \\ E-mail: leonardo@messina.med.br
}

